\title{
Problematic Behaviors of Children Undergoing Physical Therapy
}

\author{
Masayuki Uesugi \\ Department of Physical Therapy, Faculty of Rehabilitation, Kobe International University, \\ Japan
}

\section{Introduction}

According to the Japanese Ministry of Health, Labour and Welfare, there are approximately 550,000 mentally-retarded (MR) people in total, approximately 420,000 people at home and 130,000 in institutions, in Japan, including 117,000 MR children. The occurrence rate of MR children varies broadly from $0.86 \%$ to $5.6 \%$ depending on reports, but is quite high; generally 1 child out of 50 (2 to 3 per 100 births) is MR.

Mental retardation (MR) is a generic term referring to children with low intellectual capabilities and impairments in daily life and social adjustment. Their symptoms vary, including hypotonia, delayed motor development, difficulty in focusing their attention, persisting in stereotypical behavior, and delayed language development. Although MR is characterized by problematic behaviors, only a few reports address problematic behaviors of MR in general from the medical viewpoint. Scientific data on problematic behaviors of MR children is very limited. Despite illnesses that MR children are diagnosed as having, they seem to be bracketed together as MR children.

The American Association on Mental Retardation (AAMR) defines MR as "a disability characterized by significant limitations both in intellectual functioning and in adoptive behaviors as expressed in conceptual, social, and practical adaptive skills." The AAMR also states, "This disability originates before age 18." According to their definition, significant limitations in adoptive behaviors, in addition to intellectual functioning, are an integral part of MR. Problematic behaviors often observed in MR children are a cause of the abovementioned limitations in adoptive behaviors.

Physical therapists use exercise and physical therapy to help physically-handicapped adults and children improve their basic physical capabilities. Physically-handicapped children are often mentally-retarded as well. Pediatric physical therapists must increase their understanding of mental retardation, and physical therapy approaches must consider coexisting mental retardation. Development tests usually used to measure the mental retardation of handicapped children do not reveal problematic behaviors that may disturb physical therapy. In this study, mentally-retarded children are classified into two groups: those mainly suffering from mental retardation and those mainly suffering from other illnesses. The Japanese version of the Aberrant Behavior Checklist is applied to the two groups to examine if problematic behaviors differ between the two groups. 


\section{Method}

The subjects were 46 mentally-retarded children ( 32 boys and 14 girls from 1 year 4 months to 17 years 6 months with an average age of $8.6 \pm 4.6$ years) undergoing physical therapy at one of six facilities: a child daycare facility, pediatric hospital, rehabilitation facility for the handicapped, general hospital and two day-care centers. The study objectives, significance, methods, and privacy protection were explained to the caregivers of the subjects in writing, and each participant provided informed written consent.

The subjects were classified into two groups: Children diagnosed as mainly suffering from mental retardation, including chromosomal abnormality (MR group), and children diagnosed as mainly suffering from other illnesses, such as cerebral palsy and central nervous system diseases (CP group). The MR group included 23 children (15 boys and 8 girls); their average age was $8.3 \pm 5.0$ years. They were diagnosed as having mental retardation, Down syndrome, 8p-syndrome, West syndrome, nodular sclerosis, Mowat Wilson syndrome and other such illnesses (Table 1).

\begin{tabular}{|c|c|c|c|c|c|}
\hline Diagnosis & Age & SEX & GMFCS & Language & $\begin{array}{l}\text { Ryouiku } \\
\text { Techou }\end{array}$ \\
\hline & & & $\mathrm{I} \sim \mathrm{V}$ & 4 stage & 3 stage \\
\hline Mental Retardation. & $2 Y 5 \mathrm{M}$ & Female & III & Babbling & \\
\hline Chromosomal abnormality & $12 Y 1 M$ & Female & I & $\begin{array}{l}\text { Words with } \\
\text { meaning }\end{array}$ & A \\
\hline West syndrome & $6 \mathrm{Y} 6 \mathrm{M}$ & Female & IV & Babbling & A \\
\hline $\begin{array}{l}\text { Mental Retardation. } \\
\text { Frontal lobe removal }\end{array}$ & 3Y7M & Female & I & $\begin{array}{l}\text { Words with } \\
\text { meaning }\end{array}$ & B1 \\
\hline $\begin{array}{l}\text { Mental Retardation. } \\
\text { Cerebellum insect part hypoplasia }\end{array}$ & $5 Y 1 M$ & male & II & Babbling & A \\
\hline $\begin{array}{l}\text { Mental Retardation } \\
\text { Hydrocephalus }\end{array}$ & $8 Y$ & male & IV & Babbling & A \\
\hline $\begin{array}{l}\text { Cerebral Palsy. } \\
\text { West Syndrome }\end{array}$ & $4 Y 10 \mathrm{M}$ & male & IV & $\begin{array}{l}\text { Two word } \\
\text { sentences }\end{array}$ & \\
\hline West Syndrome & $5 \mathrm{Y} 1 \mathrm{M}$ & male & IV & Babbling & A \\
\hline 8 p-Syndrome & $13 Y 11 M$ & male & II & Babbling & A \\
\hline Down Syndrome & $1 Y 4 M$ & male & IV & Babbling & \\
\hline Mowat Wilson Syndrome & $5 Y 3 \mathrm{M}$ & male & V & Non verbal & A \\
\hline Mental Retardation & $15 Y 5 M$ & Female & I & Non verbal & A \\
\hline Mowat Wilson Syndrome & $7 Y 7 M$ & male & I & Non verbal & A \\
\hline Tuberous Sclerosis & $16 \mathrm{Y}$ & male & II & Babbling & A \\
\hline Mental Retardation & 9Y10M & male & II & Babbling & A \\
\hline $\begin{array}{l}\text { Chromosomal abnormality } \\
\text { Hypoglycaemic Encephalopathy }\end{array}$ & $15 Y 2 M$ & male & II & Babbling & A \\
\hline $\begin{array}{l}\text { Cerebral Palsy. } \\
\text { Mental Retardation }\end{array}$ & $15 Y 5 M$ & male & II & Non verbal & A \\
\hline Mental Retardation & $6 Y 11 M$ & Female & III & $\begin{array}{l}\text { Words with } \\
\text { meaning }\end{array}$ & A \\
\hline
\end{tabular}

Table 1. MR group. 
The CP group included 23 children (17 boys and 6 girls); their average age was $8.8 \pm 4.6$ years. They were diagnosed as having cerebral palsy, Pierre Robin syndrome, autism, aftereffects of head injuries, microcephaly, leukodystrophy, hypoxic encephalopathy, aftereffects of cerebral hemorrhages, limb palsy resulted from injuries and other such illnesses (Table 2).

\begin{tabular}{|c|c|c|c|c|c|}
\hline Diagnosis & Age & SEX & GMFCS & Language & $\begin{array}{l}\text { Ryouiku } \\
\text { Techou }\end{array}$ \\
\hline & & & $\mathrm{I} \sim \mathrm{V}$ & 4 level & 3 level \\
\hline Cerebral Palsy & $5 \mathrm{Y} 9 \mathrm{M}$ & male & III & $\begin{array}{l}\text { Two word } \\
\text { sentences }\end{array}$ & \\
\hline Pierre Robin Syndrome & $3 \mathrm{Y} 3 \mathrm{M}$ & male & I & Babbling & B1 \\
\hline Cerebral Palsy & $5 \mathrm{Y} 8 \mathrm{M}$ & male & III & $\begin{array}{l}\text { Two word } \\
\text { sentences }\end{array}$ & A \\
\hline Cerebral Palsy & $7 Y 4 M$ & male & $\mathrm{V}$ & Non verbal & \\
\hline Cerebral Palsy & $13 \mathrm{Y} 6 \mathrm{M}$ & Female & $\mathrm{V}$ & Babbling & \\
\hline Cerebral Palsy & $4 Y 7 M$ & Female & $\mathrm{V}$ & Babbling & A \\
\hline Cerebral Palsy & 4Y10M & male & $\mathrm{V}$ & Babbling & $\mathrm{A}$ \\
\hline Autism & 9Y4M & male & I & Babbling & A \\
\hline Cerebral Palsy & $7 Y 9 M$ & male & III & $\begin{array}{l}\text { Two word } \\
\text { sentences }\end{array}$ & \\
\hline Microcephaly & $16 \mathrm{Y}$ & male & $\mathrm{I}$ & $\begin{array}{l}\text { Words with } \\
\text { meaning }\end{array}$ & A \\
\hline Cerebral Palsy & $5 Y 8 M$ & male & II & Babbling & A \\
\hline Cerebral Palsy & $14 \mathrm{Y}$ & male & IV & $\begin{array}{l}\text { Two word } \\
\text { sentences }\end{array}$ & \\
\hline $\begin{array}{l}\text { Posttraumatic cerebral } \\
\text { symptom }\end{array}$ & $13 Y 7 M$ & male & II & $\begin{array}{l}\text { Two word } \\
\text { sentences }\end{array}$ & A \\
\hline Brain tumor & $16 Y 5 M$ & Female & IV & Babbling & A \\
\hline Brain tumor Epilepsy & $16 Y 4 M$ & Female & IV & Non verbal & \\
\hline $\begin{array}{l}\text { Hypoxic encephalopathy } \\
\text { Epilepsy }\end{array}$ & $6 Y 4 M$ & male & $\mathrm{V}$ & Babbling & A \\
\hline Cerebral Palsy & $15 \mathrm{Y}$ & male & IV & $\begin{array}{l}\text { Two word } \\
\text { sentences }\end{array}$ & A \\
\hline Cerebral Palsy & $9 \mathrm{Y} 2 \mathrm{M}$ & Female & II & Babbling & A \\
\hline Cerebral Palsy & $2 \mathrm{Y}$ & male & II & $\begin{array}{l}\text { Words with } \\
\text { meaning }\end{array}$ & B2 \\
\hline Cerebral Palsy & $11 Y 3 M$ & male & III & $\begin{array}{l}\text { Words with } \\
\text { meaning }\end{array}$ & A \\
\hline Cerebral Palsy & $10 Y 5 \mathrm{M}$ & Female & IV & $\begin{array}{l}\text { Two word } \\
\text { sentences }\end{array}$ & A \\
\hline Post-traumatic quadriplegia & $4 \mathrm{Y} 2 \mathrm{M}$ & male & II & Non verbal & A \\
\hline Cerebral hemorrhage sequel & $9 \mathrm{YM}$ & male & II & $\begin{array}{l}\text { Two word } \\
\text { sentences }\end{array}$ & \\
\hline
\end{tabular}

Table 2. CP group.

As for children who have ryoiku techo (certified mental disability), 14 children were classified as grade A (severe disability), 1 child as B1 (medium disability), and 1 child as B2 (light 
disability) in both groups. The examiners were 15 physical therapists, 1 occupational therapist, 2 speech therapists and 1 psychologist, 19 examiners in total, who work at the facilities/hospitals. Using the Japanese version of the Aberrant Behavior Checklist (ABC-J), each examiner assessed the problematic behaviors of mentally-handicapped children whom the examiner knew well. Other information, i.e. illnesses, age, gender, language, whether he/she has a ryoiku techo, disability grade in the ryoiku techo, if he/she has one, Gross Motor Function Classification System (GMFCS) data, were obtained from medical records and facility/hospital staff. In order to compare the severity of different problematic behavior types, the total number of children, median score, and its percentage in the total score were calculated for each of five problematic behavior types of ABC-J: irritability, lethargy, stereotypy, hyperactivity and inappropriate speech.

\section{The Aberrant Behavior Checklist}

The $A B C$ is a questionnaire developed by Aman et al. to assess problematic behaviors of mentally-handicapped persons. The $A B C$ is used for many studies, including studies on syndrome phenotypes and pharmacotherapy effects. Outside Japan, many studies use ABC. $\mathrm{ABC}$ has 58 questionnaire items in total: 15 irritability items, 16 lethargy items, 7 stereotypy items, 16 hyperactivity items, and 4 inappropriate speech items. Medical staff, parents, caretakers, and other examiners who know the subject well assess these items using a 4-point scale: No problems ( 0 point), minor problems ( 1 point), moderate problems ( 2 points), and major problems ( 3 points). Points filled in by the examiners on the score sheets indicate the severity of the problematic behavior. Since $A B C$ was developed for students of special needs education schools, it should be appropriate to assume that it targets children of six years old and upward, although it does not clearly state so. A report, however, showed that the ABC results were consistent with results of Child Behavior Checklist 2/3 and Autism Behavior Checklist, which targets 14- to 43-month old children. Using ABC for our study is appropriate.

Ryouiku Techou

Ryouiku Techou is delivered by Japanese Government to intellectual disability person. And then, It assist to consult about the intellectual disability, and to make help in various welfare systems etc. easy to receive. It is classified into three stages (A B1 B2) by the intellectual disability. A shows a serious intellectual disability, B1 shows the intellectual disability of the moderate degree, and B2 shows a slight intellectual disability. It is delivered by Japanese Government to intellectual disability person.

\section{GMFCS}

GMFCS is a 5 level classification system that describes the gross motor function of children and youth with cerebral palsy on the basis of their self-initiated movement with particular emphasis on sitting, walking, and wheeled mobility. Distinctions between levels are based on functional abilities, the need for assistive technology, including hand-held mobility devices or wheeled mobility, and to a much lesser extent, quality of movement. The focus of the GMFCS is on determining which level best represents the child's or youth's present abilities and limitations in gross motor function. Children who have motor problems similar to those classified in "Level I" can generally walk without restrictions but tend to be limited in some of the more advanced motor skills. Children whose motor function has been classified at "Level V" are generally very limited in their ability to move themselves around even with the use of assistive technology. 


\section{Results}

Irritability was observed in $18 \mathrm{MR}$ group children and $23 \mathrm{CP}$ group children. Lethargy was observed in $19 \mathrm{MR}$ group and $21 \mathrm{CP}$ group children, stereotypy in 11 and 12 children, hyperactivity in 21 and 21 children and inappropriate speech in 9 and 10 children (Figure 1).

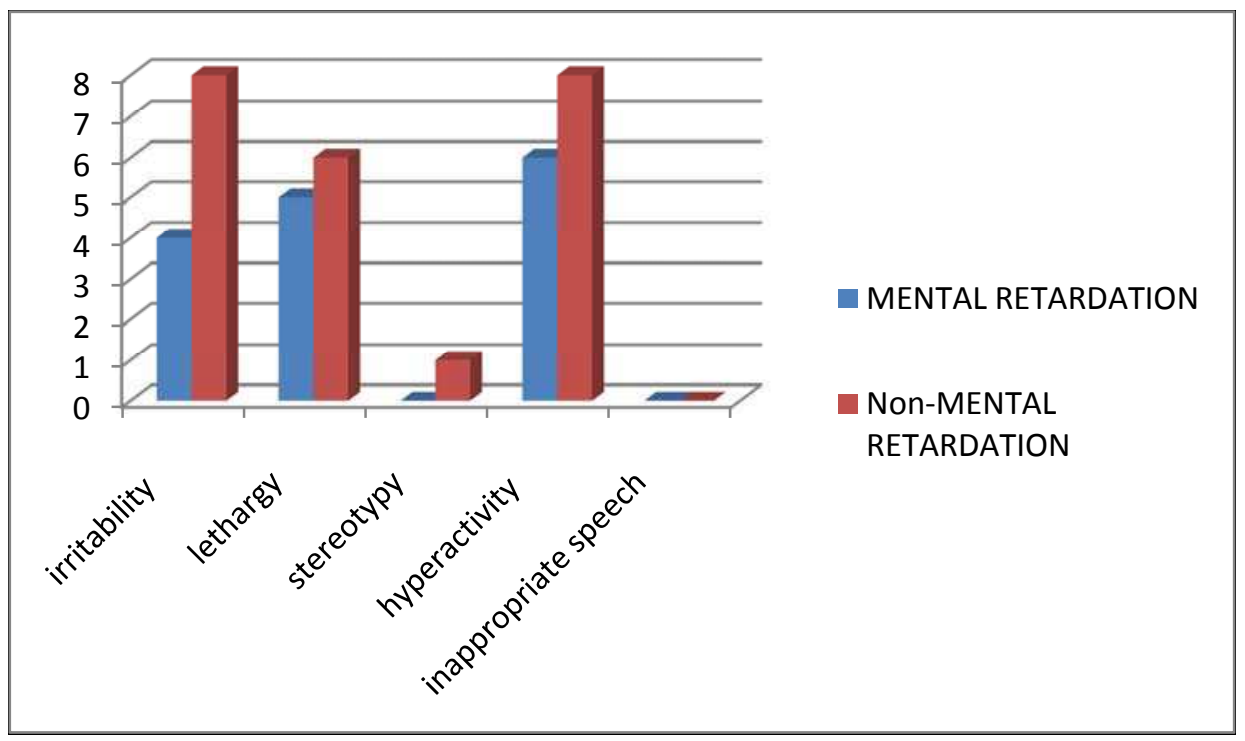

Fig. 1. Number of subjects with problematic behaviors - MR and CP groups.

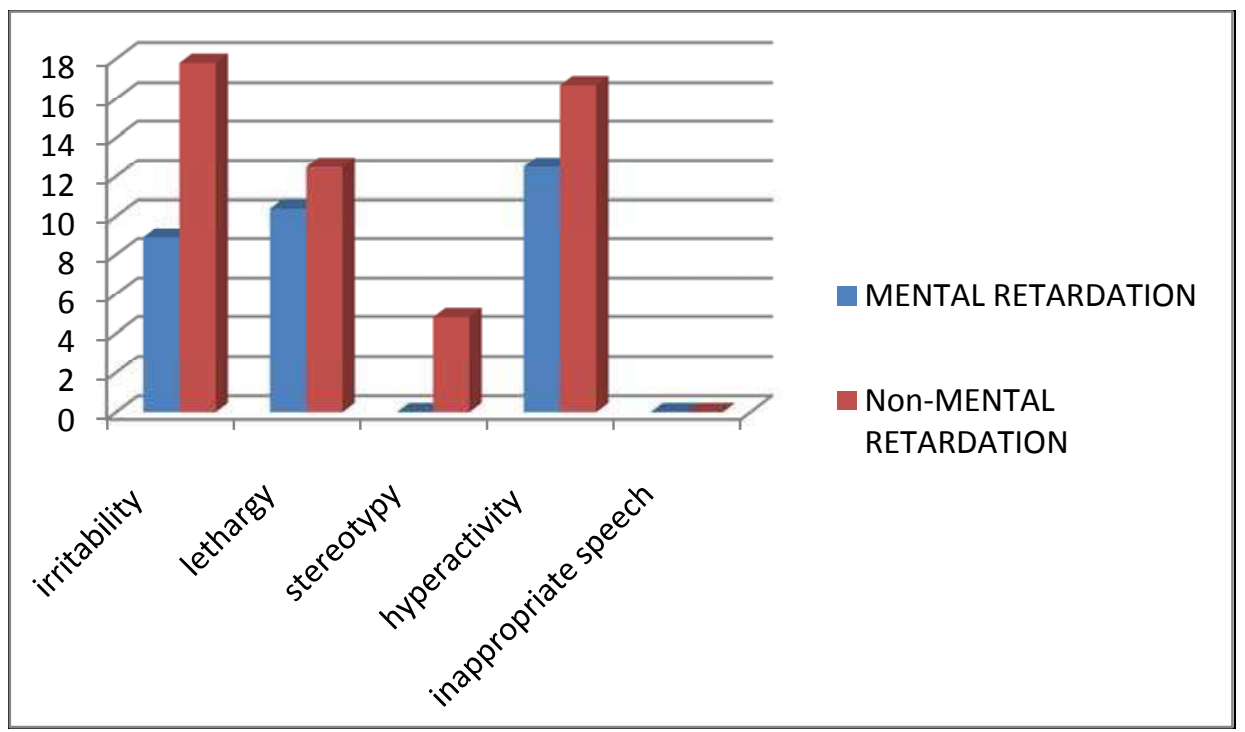

Fig. 2. Median - MR and CP groups. 
For irritability, the median was 4 for the MR group and 8 for the $\mathrm{CP}$ group, and its percentage in the total score was $8.9 \%$ for the MR group and $17.8 \%$ for the CP group. They were $5(10.4 \%)$ and $6(12.5 \%)$ for lethargy, $0(0 \%)$ and $1(4.8 \%)$ for stereotypy, $6(12.5 \%)$ and 8 $(16.7 \%)$ for hyperactivity, and $0(0 \%)$ and $0(0 \%)$ for inappropriate speech. (Figure $2 \cdot 3)$.

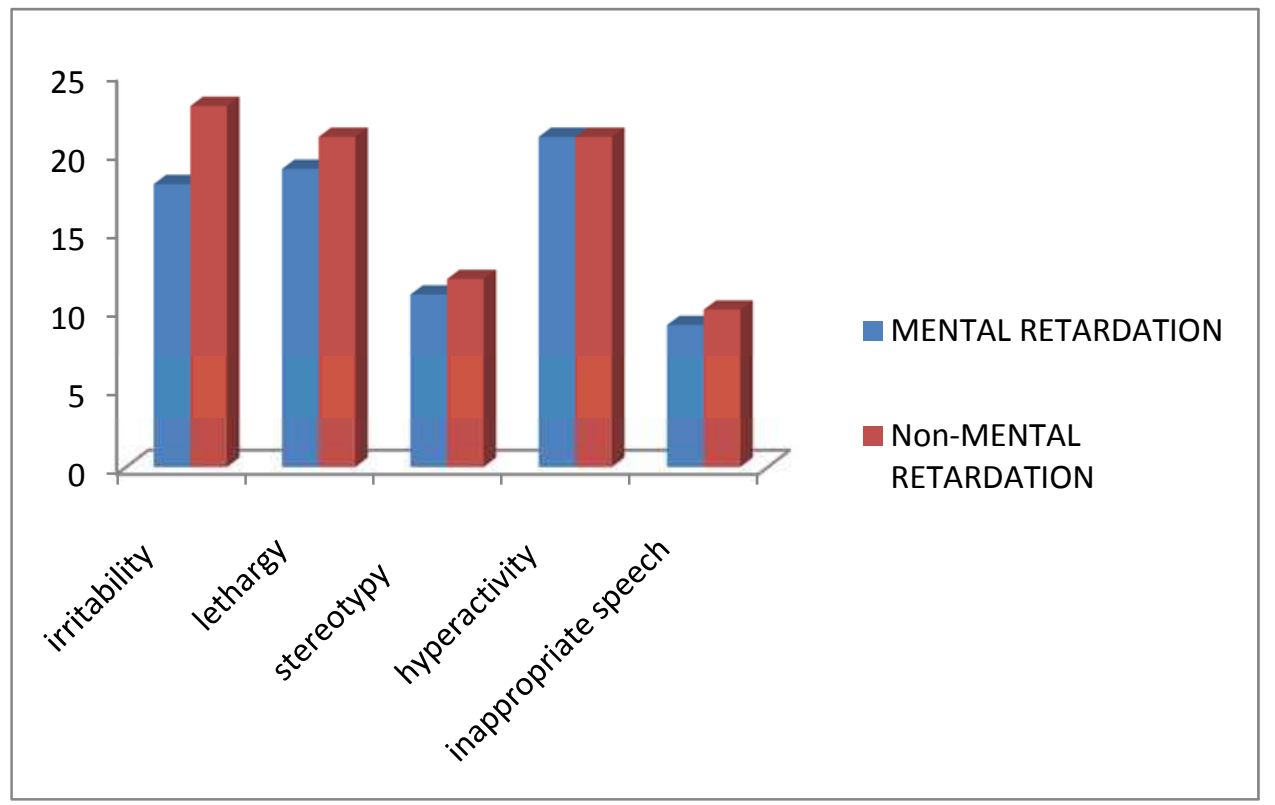

Fig. 3. Percentage in the total score $-\mathrm{MR}$ and $\mathrm{CP}$ groups.

\section{Discussion}

Methods for assessing problematic behaviors

Appropriate assessment methods are required to accurately understand problematic behaviors. We looked extensively, but all we could find in Japan were an ADHD Scale for assessing attention deficit and hyperactivity, DS behavior test for the aging of Down syndrome patients, assessment scale for the adoptive behaviors of most severely mentallyretarded people ${ }^{24}$, and questionnaire for students of special needs education schools.

Studies on problematic behaviors

Clarks et al. used $A B C$ to assess problematic behaviors of patients suffering from three mental retardation syndromes caused by chromosomal abnormality: Prader-Willi, SmithMagenis, and cri du chat syndromes. They reported that hyperactivity is the largest problem for cri du chat syndrome patients, irritability for Prader-Willi syndrome patients, and impulsiveness for Smith-Magenis syndrome patients. Clarks et al. also assessed Angelman syndrome patients using ABC-J. Inappropriate smile, considered to characterize this syndrome, is observed in only $57 \%$ of patients, whereas $68 \%$ of patients showed interest in water and $64 \%$ of patients had eating disorders. Mount et al. studied Rett syndrome patients and severely mentally-retarded people. The percentage of Rett syndrome patients showing 
stereotypic hand movement, considered to characterize Rett syndrome, was similar to the percentage of mentally-retarded people showing stereotypic behaviors. These studies reveal characteristics of MR children who show various symptoms, and also help to determine if symptoms considered to characterize these syndromes are really characteristic of them.

\section{Cerebral palsy and mental retardation}

Physical therapists often treat mentally-retarded children with cerebral palsy $(\mathrm{CP})$. For each GMFCS level, the percentages of severe mental retardation and problematic behaviors were reported as follows: In Level I (capable of going up and down the stairs), children with severe MR accounted for approximately $5 \%$ or less and children with problematic behaviors also accounted for approximately $5 \%$ or less. They were approximately $20 \%$ and $5 \%$ or less in Level II (capable of walking), approximately $30 \%$ and $5 \%$ or less in Level III (capable of walking with assistive mobility devices), approximately $25 \%$ and $5 \%$ or less in Level IV (capable of using electric-powered wheelchairs), and approximately $85 \%$ and $10 \%$ in Level V (self mobility is limited even with electric-powered wheelchairs). The higher the motor functions, the lower the percentages of children showing mental retardation and problematic behaviors. According to Carlsson et al., mental retardation is observed in $45 \%$ of children with CP and $25 \%$ of them are severely mentally-retarded. Twenty-five percent of parents of children with cerebral palsy assess their children as behaving abnormally, and $18 \%$ assessed their children as being on the borderline. Children with cerebral palsy are known to have higher risks of behavioral and psychological problems than healthy children. These issue, however, await further studies.

There is a disease of Uner Tan syndrome though not contained in the subjects of this study. Uner Tan syndrome is characterized by habitual quadrupedalism, impaired intelligence, and rudimentary speech was discovered in a small village near Iskenderun, and families were later found in Adana and two other small villages near Gaziantep and Canakkale. In all the affected individuals dynamic balance was impaired during upright walking, and they habitually preferred walking on all four extremities. MRI scans showed inferior cerebellovermian hypoplasia with slightly simplified cerebral gyri in three of the families, but appeared normal in the fourth. PET scans showed a decreased glucose metabolic activity in the cerebellum, vermis and, to a lesser extent the cerebral cortex, except for one patient, whose MRI scan also appeared to be normal. All four families had consanguineous marriages in their pedigrees, suggesting autosomal recessive. The syndrome was genetically heterogeneous. Since the initial discoveries more cases have been found, and these exhibit facultative quadrupedal locomotion, and in one case, late childhood onset. Uner was described as follows. It has been suggested that the human quadrupedalism may, at least, be a phenotypic example of reverse evolution. From the viewpoint of dynamic systems theory, it was concluded there may not be a single factor that predetermines human quadrupedalism in Uner Tan syndrome, but that it may involve selforganization, brain plasticity, and rewiring, from the many decentralized and local interactions among neuronal, genetic, and environmental subsystems. I think that such an aspect might be necessary of impaired intelligence.

Mental retardation of facility users

According to the National Liaison Council of Four Development Support Facilities Organizations, out of 2,609 children attending schools for mentally retarded children, $56.0 \%$ had severe MR, 30.6\% had medium MR, and $8.7 \%$ had autism. Koike reported that out of 
145 children who came to the pediatric rehabilitation department, 54 children had cerebral palsy or other cerebral disorders, and 43 children out of the 54 children also had MR.

The author et al. assessed 26 mentally-retarded children undergoing pediatric physical therapy at one of three facilities, including a child daycare facility. Examiners were a physical therapist and other medical practitioners working at the facilities. Assessment was made using ABC-J. Out of the 26 children, irritability was observed in 23 children, lethargy in 23 , stereotypy in 13 , hyperactivity in 23 , and inappropriate speech in 12.

Tada reported that $55 \%$ of services provided by physical therapists at special needs education schools are for physically-handicapped children, including individual counseling for physically-handicapped children and lectures concerning physical disabilities. Physical therapists' services for mentally-retarded children, however, also account for a high percentage, 30.4\%, including individual counseling for mentally-retarded children and lectures concerning mental retardation. Tada's report suggests that physical therapists are often involved with mental retardation and mentally-retarded children.

Significance of this study

From the above, studying problematic behaviors of MR children is important. In this study, more $\mathrm{CP}$ group children showed problematic behaviors than the MR group children in all types of problematic behaviors, except hyperactivity. Except inappropriate speech, where the median and its percentage in the total score were 0 in both groups, the scores were always higher in the $\mathrm{CP}$ group than the MR group. Although no statistical significance was observed, more subjects had problematic behaviors, and their degrees of problematic behaviors were higher, in the $\mathrm{CP}$ group than in the MR group. This suggests that MR children undergoing physical therapy, regardless of whether they are primarily suffering from mental retardation or other illness, are likely to have many problematic behaviors. Iwasaka studied problematic behaviors of $84 \mathrm{MR}$ children at a school for physically handicapped or mentally retarded children. Iwasaka reported that allotriophagy, swallowing food without chewing, and finger sucking increase when children grow, and being unable to get out of bed, dependency, sleep disorders, decrease in movement, panicking, biting nails and problematic sexual behaviors decrease with age. This suggests that subject age must be considered when studying their problematic behaviors.

This study has the following limitations: The subjects were selected only because they use one of the six facilities and the examiners could easily include them in the study. The examiners knew the subjects well, but how much they knew them varied. The author subjectively judged whether the subjects are mainly suffering from MR or other illnesses and classified them into the two groups. Problematic behaviors due to MR are a major disturbance in pediatric physical therapy. However, few studies address problematic behaviors from the medical viewpoint. Despite such limitations, this study has significance and offers new contributions as a physical therapy study.

\section{Summary}

This study classified mentally-retarded children undergoing pediatric physical therapy into two groups: children mainly suffering from mental retardation and children mainly suffering from other illnesses, and examined whether their problematic behaviors differ. The subjects were 46 mentally-retarded children undergoing physical therapy at one of six 
facilities, including a child daycare facility and pediatric hospital. The examiners were 19 medical practitioners, including physical therapists, working at the facilities. Problematic behaviors were assessed using the Japanese version of the Aberrant Behavior Checklist. The subjects were classified into two groups: children diagnosed as mainly suffering from mental retardation (MR group) and children diagnosed as mainly suffering from other illnesses (CP group). In order to compare the severity of five problematic behavior types, the total number of children, median score, and its percentage in the total score were calculated for each problematic behavior type. More $\mathrm{CP}$ group children showed problematic behaviors than the MR group children in all types of problematic behaviors, except hyperactivity. Except inappropriate speech, where the median and its percentage in the total score were 0 in the both groups, more subjects had problematic behaviors, and their degrees of problematic behaviors were higher, in the $\mathrm{CP}$ group than in the MR group, although no statistical significance was observed. This suggests that MR children undergoing physical therapy, regardless of whether they are diagnosed as mainly suffering from mental retardation or other illness, are likely to have many problematic behaviors.

Keywords : handicapped children · physical therapy · problematic behaviors

\section{Acknowledgement}

We acknowledge all staff at the hospitals and facilities participating in this study, the children and their parents for their understanding and assistance.

\section{Conclusions}

- Physical therapy approaches must consider coexisting mental retardation.

- The subjects are classified into two groups

- Two groups are those mainly suffering from mental retardation and those mainly suffering from other illnesses.

- The Japanese version of the Aberrant Behavior Checklist is applied to the two groups . the median and its percentage in the total score are calculated for each problematic behavior type from the assessment results.

- This suggests that MR children undergoing physical therapy, regardless of whether they are diagnosed as mainly suffering from mental retardation or other illness, are likely to have many problematic behaviors

\section{References}

Aman MG, Singh NN(Ono yosio), 2006: Japaniese manuals of Aberrant Behavior Checklist. Jiho. Tokyo. Japan

Aman MG, Singh NN, 1986: Aberrant Behavior Checklist-community, Slosson educational publication,inc, New York. USA

Aman MG, 2009: Validity of the aberrant behavior checklist in a clinical sample of toddlers, Child Psychiatry Hum Dev.; 40:99-110. USA

Atsushi Kanno and Yukiko Ikeda1, 998: Good Life for Down Syndrome Patients - Understanding and Supporting Adult Patients, Fukumura Publication, Tokyo:186-187.Japan

Cabinet Office, 2009: White Paper on the Handicapped Japan

Clarke DJ, Marston G, 2000 :Problem behaviors associated with 15q-Angelman syndrome. Am J Ment Retard. 105:25-31.USA 
Clarks D,Boer H, 1998: problem behaviors asssociated with deletion prader-willi,smith-magenis,and cri du chat syndromes :American journal on mental retardation, 103:264-271.USA

Dykens EM, Clarke DJ, 1998: Correlates of Maladaptive behavior in individuals with $5 p$-(cri du chat) syndorome Dev Med Chil Neuro, 1997, 39:752-756.USA

Emergency General Meeting, 2006: National Liaison Council of Four Development Support Facilities Organizations, Japan

Gabriels RL, Cuccaro ML, Hill DE,et al, 2005: Repetitive behaviors in autism: relationships with associated clinical features. Res Dev Disabil. 26: 169-81.USA

Graham JM Jr, Rosner B, Dykens E, et al, 2005: Behavioral features of CHARGE syndrome (HallHittner syndrome) comparison with Down syndrome, Prader-Willi syndrome, and Williams syndrome. Am J Med genet A, 15: 240-247.USA

Hideaki Senju (Edited), 2007 : Physical Therapy for Children $2^{\text {nd }}$ edition, Shinryo Bunko, Kobe, Japan

Hidemi Iwasaka, 1995: Problematic Behaviors of Mentally-Retarded Children, Journal of Nara Medical Association, 46: 114-126. Japan

http:// motorgrowth.canchild.ca/en/GMFCS/expandedandrevised.asp

Junko koike, 2003: Current state and view of child's rehabilitation. Rigaku Ryoho Journal , 37: 363-371. Japan

Kau AS, Tierney E, Bukelis I, et al, 2004: Social behavior profile in young males with fragile X syndrome: characteristics and specificity. Am J Med Genet A, 126: 9-17.USA

Kau AS, Reider EE, Payne L, et al, 2000: Early behavior signs of psychiatric phenotypes in fragile $X$ syndrome. Am J Ment Retard. 105: 286-99.USA

Kazuho Jinnai, Norihiko Ando, and Toshiyuki Ito, 2007: Rehabilitation Medicine for Children, Igaku Shoin, Tokyo, Japan

Karen Dodd, Christine Imms, and Nicholas F. Taylor, 2010: Physiotherapy and Occupational Therapy for People with Cerebral Palsy: A Problem-Based Approach to Assessment and Management, Mac Keith Press, UK

Kenji Yokochi, 2005: Assessment of Adoptive Behaviors of Most Severely Mentally-Retarded Children and People, Brain and Development 37, Japan

Kenji Yokochi, 2005: Assessment of Adoptive Behaviors of Most Severely Mentally-Retarded Children and People, Brain and Development 37:4-9, Japan

Masayuki Uesugi, Susumu Naruse, Yuri Inoue, et al, 2010: What Problematic Behaviors are Observed among Mentally Handicapped Children Receiving Pediatric Physical Therapy? Journal of Physical Therapy Science22 387-390. Japan

Ministry of Health, Labour and Welfare, 2005: Basic Survey on Mentally Retarded Children and People,. Japan

Mount RH, Hastings RP, Reilly S,et al, 2002: Behaviour problems in adult women with Rett syndrome. J Intellect Disabil Res. 46:619-24.USA

Naomi Hanzawa, 2004: Rehabilitation of Children - Coping with Clinical Conditions and Life Stages, Kanahara Publishing, Tokyo. Japan

Tatsuo Sakamoto, 1985: How to Understand Handicapped Children - Clinical Observation and Examination Methods, Gakuensha, Tokyo:176-177.Japan

Tomomi Tada, 2009: Roles of Physical Therapists at Schools for Handicapped Children, Rigaku Ryoho Journal, 44: 417-425. Japan

Uner Tan, 2010: Uner tan syndrome: history, clinical evaluations, genetics, and the dynamics of human quadrupedalism: The open neurology journal.; 4:78-89. 


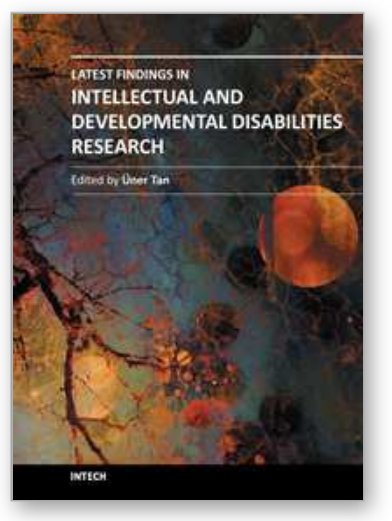

\author{
Latest Findings in Intellectual and Developmental Disabilities \\ Research \\ Edited by Prof. Uner Tan
}

ISBN 978-953-307-865-6

Hard cover, 404 pages

Publisher InTech

Published online 15, February, 2012

Published in print edition February, 2012

Intellectual and Developmental Disabilities presents reports on a wide range of areas in the field of neurological and intellectual disability, including habitual human quadrupedal locomotion with associated cognitive disabilities, Fragile $X$ syndrome, autism spectrum disorders, Down syndrome, and intellectual developmental disability among children in an African setting. Studies are presented from researchers around the world, looking at aspects as wide-ranging as the genetics behind the conditions to new and innovative therapeutic approaches.

\title{
How to reference
}

In order to correctly reference this scholarly work, feel free to copy and paste the following:

Masayuki Uesugi (2012). Problematic Behaviors of Children Undergoing Physical Therapy, Latest Findings in Intellectual and Developmental Disabilities Research, Prof. Uner Tan (Ed.), ISBN: 978-953-307-865-6, InTech, Available from: http://www.intechopen.com/books/latest-findings-in-intellectual-and-developmental-disabilitiesresearch/problematic-behaviors-of-children-undergoing-physical-therapy

\section{INTECH}

open science | open minds

\section{InTech Europe}

University Campus STeP Ri

Slavka Krautzeka 83/A

51000 Rijeka, Croatia

Phone: +385 (51) 770447

Fax: +385 (51) 686166

www.intechopen.com

\section{InTech China}

Unit 405, Office Block, Hotel Equatorial Shanghai

No.65, Yan An Road (West), Shanghai, 200040, China

中国上海市延安西路65号上海国际贵都大饭店办公楼 405 单元

Phone: +86-21-62489820

Fax: +86-21-62489821 
(C) 2012 The Author(s). Licensee IntechOpen. This is an open access article distributed under the terms of the Creative Commons Attribution 3.0 License, which permits unrestricted use, distribution, and reproduction in any medium, provided the original work is properly cited. 